Pacific Journal of Mathematics

CONTINUOUS PRODUCTS AND NONLINEAR INTEGRAL 


\title{
CONTINUOUS PRODUCTS AND NONLINEAR INTEGRAL EQUATIONS
}

\author{
J. W. NEUBERGER
}

1. Introduction. J. S. MacNerney [2] has expressed the solution $M$ of the Stieltjes integral equation

$$
M(x, t)=1+\int_{x}^{t} d F(u) \cdot M(u, t)
$$

as a continuous product

$$
M(x, t)={ }_{x} \Pi^{t}\left[1+d F^{\prime}\right]
$$

in case $F$ is a function from the real numbers into the space $B$ of continuous linear transformations from a normed, linear and complete space $S$ into $S$, which is continuous and of bounded variation on each interval. This is a generalization of the familiar relationship

$$
e^{t-x}=1+\int_{x}^{t} e^{t-u} d u, e^{t-x}=\lim _{n \rightarrow \infty}\left[1+\frac{t-x}{n}\right]^{n} .
$$

The object of this paper is to extend these considerations to a larger class of integral equations including nonlinear equations. The space $S$ is required to be an additive abelian group with zero element $N$, having a norm $\|\cdot\|$ such that, if $x$ and $y$ are in $S$ then $\|x\|>0$ unless $x=N$, and $\|-x\|=\|x\|,\|x+y\| \leqq\|x\|+\|y\|$. The space $S$ is complete with respect to the metric induced by this norm. The function $F$ from a number interval into the set $B$ of all continuous transformations from $S$ into $S$ is required to satisfy certain inequalities (Theorem $\mathrm{A}^{\prime}, \S 3$ ).

In $\S 2$ we develop a continuous product in a still more general setting, requiring only that $S$ should be a complete metric space, and then specialize in $\S 3$. Having in mind the problem of numerical solution of differential and integral equations, we give particular attention to obtaining upper bounds to the errors in various approximations to the continuous product ( $\S \S 3$ and 4 ).

In $\S 5$, integral equations of the form

$$
Y(t)=A+\int_{c}^{t} d F \cdot Y
$$

are solved by means of the continuous product. Section 6 contains

Presented to the Society, August 30, 1957; received by the editors December 23, 1957. This paper is based for the most part on the author's thesis prepared under the supervision of Professor H. S. Wall at the University of Texas. 
examples illustrating the application of the theory to certain special cases.

2. Continuous products in a complete metric space. Suppose $S$ is a complete metric space with distance function $D$ and $B$ the set of all continuous transformations from $S$ into $S$. If $F$ is in $B$ then $F x$ denotes the image of the point $x$ of $S$ under $F$; if $G$ is in $B$ then $F G$ is the element $H$ of $B$ defined by $H x=F(G x)$. If $n$ is a positive integer and each of $F_{1} \cdots, F_{n}$ is an element of $B$ then

$$
\prod_{i=1}^{0} F_{i}=I \text { and } \prod_{i=1}^{j} F_{i}=F_{j}\left[\prod_{i=1}^{j-1} F_{i}\right], \quad j=1, \cdots, n,
$$

where $I$ is the identity transformation.

If $u$ and $v$ are numbers then $J$ is a chain from $u$ to $v$ if $J$ is an increasing or decreasing finite number sequence whose first term is $u$ and whose last term is $v$; the chain from $u$ to $u$ is the two-term sequence $u, u$. If $J$ is the chain $\left\{x_{i}\right\}_{i=1}^{n+1}$ from $u$ to $v$ then the mesh of $J$ is the least number $r$ such that $\left|x_{i+1}-x_{i}\right| \leqq r, i=1, \cdots, n$. The statement that $J^{\prime}$ is a refinement of $J$ means that $J^{\prime}$ is a chain from $u$ to $v$ having $J$ as subsequence. The statement that $J^{\prime \prime}$ is the section of $J$ from the number $u^{\prime}$ of $J$ to the number $v^{\prime}$ of $J$ means that $J^{\prime \prime}$ is the subsequence of $J$ which is a chain from $u^{\prime}$ to $v^{\prime}$ and a proper subsequence of no subsequence of $J$ which is a chain from $u^{\prime}$ to $v^{\prime}$.

Suppose $[a, b]$ is a number interval, $T$ a transformation from the square disc $[a, b] \times[a, b], A$ a point of $S$ and $J$ the number sequence $\left\{t_{i}\right\}_{i=1}^{n+1}$ contained in $[a, b]$. Then $T\left(t_{i+1}, t_{i}\right)$ is denoted by $T_{i}, J$. If, in addition, $T$ is a transformation to $B$ then $\left[\prod_{i=1}^{n} T_{i}, J\right] A$ is denoted by $\Pi_{J}(T, A)$. The statement that $x$ is the continuous product

$$
{ }_{c} \Pi^{t}(T, A)
$$

means each of $c$ and $t$ is a number in $[a, b], x$ is a point of $S$ and, if $\varepsilon$ is a positive number then there is a chain $J$ from $c$ to $t$ such that $D\left\{\Pi_{J^{\prime}}(T, A), x\right\}<\varepsilon$ for every refinement $J^{\prime}$ of $J$.

The statement that $V$ is a variation function for $[a, b]$ means that $V$ is a continuous function from $[a, b] \times[a, b]$ into the non-negative numbers such that, if each of $x, y$, and $z$ is in $[a, b]$ and $x \leqq y \leqq z$, then $V(x, y)+V(y, z) \leqq V(x, z)=V(z, x)$. Note that $0 \leqq V(x x)+V(x, x) \leqq$ $V(x, x)$, so that $V(x, x)=0$. The statement that $W$ is a closing function for $[a, b]$ means that $W$ is a variation function for $[a, b]$ such that, if $\varepsilon$ is a positive number then there is a chain $J=\left\{t_{i}\right\}_{i=1}^{n+1}$ from $a$ to $b$ such that $\sum_{i=1}^{n} W_{i, J}<\varepsilon$. If each of $U$ and $V$ is a variation function for $[a, b]$, then $U \cdot V$ is a closing function for $[a, b]$. If $W$ is a closing function for $[a, b]$ and $[c, d]$ is a subinterval of $[a, b]$, the contraction of $W$ to $[c, d] \times[c, d]$ is a closing function for $[c, d]$. 
THEOREM A. Suppose $[a, b]$ is a number interval, $T$ a function from the square disc $[a, b] \times[a, b]$ into $B, A$ a point of $S, r$ a positive number, $c$ in $[a, b]$, each of $U$ and $V$ a variation function for $[a, b], W$ a closing function for $[a, b]$. Suppose further that for $p$ and $q$ in $[a, b], J$ a chain from $p$ to $g, x$ and $y$ in $S, D\{x, A\} \leqq r$ and $D\{y, A\} \leqq r$, we have

(1) $D\{T(p, q) x, T(p, q) y)\} \leqq[1+U(p, q)] D(x, y)$,

(2) $D\{T(p, q) x, x\} \leqq V(p, q)$

and (3) if $D\left\{\Pi_{J^{\prime}}(T, x), A\right\} \leqq r$ for each chain $J^{\prime}$ from $p$ to a number $t$ in $[a, b]$ such that $|p-t|+|t-q|=|p-q|$, then $D\left\{\Pi_{J}(T, x)\right.$, $T(q, p) x\} \leqq W(p, q)$.

Then there is a subinterval $Q^{\prime}$ of $[a, b]$ containing $c$ such that, if $t$ is in $Q^{\prime}$ and $J$ is a chain from $c$ to $t$ then $D\left\{\Pi_{J}(T, A), A\right\} \leqq r$; and if $Q$ is such an interval and $t$ is in $Q$ then the continuous product ${ }_{c} \Pi^{t}(T, A)$ is a point of $S$.

Proof. We first establish statements (i) and (ii) below, and then the theorem.

Denote by $Q^{\prime}$ a subinterval $Q^{\prime \prime}$ of $[a, b]$ containing $c$ such that if $t$ is in $Q^{\prime \prime}$ then $V(c, t) \leqq r$.

(i) If $J$ is the chain $\left\{s_{i}\right\}_{i=1}^{n+1}$ from $c$ to the number $t$ in $Q^{\prime}$ then

$$
D\left\{\Pi_{J}(T, A), A\right\} \leqq V(c, t) .
$$

For, $\left[\prod_{i=1}^{0} T_{i, J}\right] A=A$ so that

$$
D\left\{\left[\Pi_{i=1}^{0} T_{i, J}\right] A, A\right\}=0 \leqq V\left(c, s_{1}\right) .
$$

Suppose there is a positive integer $k$ not greater than $n$ such that $D\left\{\left[\prod_{i=1}^{k} T_{i, J}\right] A, A\right\}>V\left(c, s_{k+1}\right)$ and denote by $j$ the least such integer $k$. If $m$ is a positive integer not greater than $j$ then

$$
D\left\{\left[\prod_{i=1}^{m-1} T_{i, J}\right] A, A\right\} \leqq V\left(c, s_{m}\right) \leqq V(c, t) \leqq r
$$

Then,

$$
\begin{aligned}
D\left\{\left[\prod_{i=1}^{j} T_{i, J}\right] A, A\right\} \leqq \sum_{u=1}^{j} D\{ & {\left.\left[\prod_{i=1}^{u} T_{i, J}\right] A,\left[\prod_{i=1}^{u-1} T_{i, J}\right] A\right\} } \\
& =\sum_{u=1}^{j} D\left\{T_{u, J}\left[\prod_{i=1}^{u-1} T_{i, J}\right] A,\left[\prod_{i=1}^{u-1} T_{i, J}\right] A\right\}
\end{aligned}
$$

which, by (2.2) and (2) of the hypothesis, does not exceed $\sum_{u=1}^{j} V_{u, J} \leqq$ $V\left(c, s_{j+1}\right)$, a contradiction; and (i) is established. Thus $Q^{\prime}$ is a subinterval of $[a, b]$ containing $c$ such that if $t$ is in $Q^{\prime}$ and $J$ is a chain from $c$ to $t$ then $D\left\{\prod_{J}(T, A), A\right\} \leqq r$.

Suppose that $Q$ is a subinterval of $[a, b]$ which contains $c$ such that, 
if $t$ is in $Q$ and $J$ is a chain from $c$ to $t$ then $D\left\{\Pi_{J}(T, A), A\right\} \leqq r$.

(ii) If $t$ is in $Q, J$ is the chain $\left\{s_{i}\right\}_{i=1}^{n}$ from $c$ to $t$ and $J^{\prime}$ a refinement of $J$ then

$$
D\left\{\prod_{J}(T, A), \prod_{J^{\prime}}(T, A)\right\} \leqq W_{n, J}+\sum_{i=2}^{n} W_{i, J} \prod_{u=i}^{n}\left[1+U_{u, J}\right]
$$

To prove this, suppose $J^{\prime}$ is the refinement $\left\{t_{i}\right\}_{i=1}^{m+1}$ of $J$ and, if $u_{j}$ is the integer $k$ such that $s_{j+1}=t_{k+1}, j=0, \cdots, n$, then

$$
L_{j}=\left[\prod_{p=1}^{j} T_{p, J}\right] A \text { and } M_{\mathfrak{j}}=\left[\prod_{p=1}^{u_{\jmath}} T_{p, J^{\prime}}\right] A, j=1, \cdots, n \text {. }
$$

If $\left\{v_{\iota}\right\}_{i=1}^{k+1}$ is the section $K$ of $J^{\prime}$ from $s_{j}$ to $s_{j+1}$ then

$$
\begin{aligned}
D\left\{M_{j}, L_{j}\right\} & =D\left\{\left[\prod_{i=1}^{k} T_{i, K}\right] M_{j-1}, T_{\jmath, J} L_{j-1}\right\} \\
& \leqq D\left\{\left[\prod_{i=1}^{k} T_{i, K}\right] M_{j-1}, T_{j, J} M_{j-1}\right\}+D\left\{T_{j, J} M_{j-1}, T_{j, J} L_{j-1}\right\} .
\end{aligned}
$$

Since $D\left\{\Pi_{J^{\prime \prime}}\left(T, M_{j-1}\right), A\right\} \leqq r$ for each chain $J^{\prime \prime}$ from $s_{j}$ to a number $t^{\prime}$ such that $\left|s_{j}-t^{\prime}\right|+\left|t^{\prime}-s_{j+1}\right|=\left|s_{j}-s_{j+1}\right|$ then we have from (1) and (3) of the hypothesis,

$$
D\left\{M_{\jmath}, L_{j}\right\} \leqq W_{j, J}+\left[1+U_{j, J}\right] D\left\{M_{j-1}, L_{j-1}\right\} .
$$

Thus, $D\left\{M_{1}, L_{1}\right\} \leqq W_{1, J}, D\left\{M_{2}, L_{2}\right\} \leqq W_{2, J}+W_{1, J}\left[1+U_{2, J}\right]$ and, by mathematical induction, (2.3) is established.

Since

$$
\exp [U(c, t)] \geqq \prod_{u=1}^{n}\left[1+U_{u J}\right], \quad i=1, \cdots, n,
$$

it follows from (2.3) that

$$
D\left\{\prod_{J}(T, A), \prod_{J^{\prime}}(, A)\right\} \leqq\{\exp [U(c, t)]\} \sum_{i=1}^{n} W_{i, J} \cdot
$$

If $\varepsilon$ is a positive number and the chain $J$ from $C$ to $t$ in $Q(=[\alpha, \beta])$ is such that $\sum_{i=1}^{n} \mathrm{~W}_{i, j}<\varepsilon \mid\{\exp [U(\alpha, \beta)]\}$, then $D\left\{\Pi_{J}(T, A), \Pi_{J^{\prime}}(T, A)\right\}<\varepsilon$ for every refinement $J^{\prime}$ of $J$. Since the space $S$ is complete, it follows that, for each $t$ in $Q$, there is a point in $S$ which is the continuous product ${ }_{c} \Pi^{t}(T, A)$.

Denote by $Y$ the function from $Q$ into $S$ such that $Y(t)={ }_{c} \Pi^{t}(T, A)$ for each $t$ in $Q$.

Corollary 1. Suppose that $t$ is in $Q$, s between $c$ and $t$ and $J$ the chain $\left\{s_{i}\right\}_{i=1}^{n+1}$ from $s$ to $t$. Then $D\left\{\Pi_{J^{\prime}}(T, Y(s)), A\right\} \leqq r$ for each chain $J^{\prime}$ from $s$ to a number $u$ such that $|s-u|+|u-t|=|s-t|$, and $D\left\{\Pi_{J}(T\right.$, $Y(s)), Y(s)\} \leqq V(s, t)$. 
Proof. We have $D\{Y(s), A\} \leqq r$ since $D\left\{\prod_{J^{\prime \prime}}(T, A), A\right\} \leqq r$ for each $J^{\prime \prime}$ from $c$ to $s$. If $J^{\prime}$ is a chain from $s$ to a number $u$ such that $|s-u|+|u-t|=|s-t|$ then $D\left\{\Pi_{J^{\prime}}(T, Y(s)), A\right\} \leqq r$ since $D\left\{\Pi_{J^{\prime}}(T\right.$, $\left.\left.\Pi_{J^{\prime \prime}}(T, A)\right), A\right\} \leqq r$ for each chain $J^{\prime \prime}$ from $c$ to $s$ and the function $h$ defined by $h(x)=\Pi_{J^{\prime}}(T, x)$ for all $x$ in $S$, is continuous.

Thus

$$
D\left\{\left[\prod_{i=1}^{0} T_{i, J}\right] Y(s), Y(s)\right\}=0 \leqq V\left(s, s_{1}\right) .
$$

The fact that $D\left\{\Pi_{J}(T, Y(s)), Y(s)\right\} \leqq V(s, t)$ follows by an argument by mathematical induction similar to the one used in (i) in the proof of Theorem A.

CoRollary 2. If $t$ is in $Q, s$ between $c$ and $t, J_{1}$ a chain from $c$ to $t$ and $J$ the chain $\left\{s_{i}\right\}_{i=1}$ from $s$ to $t$, then

$$
D\left\{\prod_{J}\left(T, \prod_{J_{1}}(T, A)\right), \prod_{J}(T, Y(s))\right\} \leqq D\left\{\prod_{J_{1}}(T, A), Y(s)\right\}\{\exp [U(s, t)]\} .
$$

Proof. Denote $\Pi_{J_{1}}(T, A)$ by $x$ and $Y(x)$ by $y$. By Corollary 1 we have

$$
D\left\{\left[\prod_{i=1}^{j} T_{i, J}\right] y, A\right\} \leqq r, \quad j=0, \cdots, n .
$$

Since $D\left\{\left[\prod_{i=1}^{j} T_{i, J}\right] x, A\right\} \leqq r, j=0, \cdots, n$, we have

$$
\begin{aligned}
& D \\
& \quad\left\{\prod_{J}(T, x), \prod_{J}(T, y)\right\}=D\left\{T_{n, J}\left[\prod_{i=1}^{n-1} T_{i, J}\right] x, T_{n, J}\left[\prod_{i=1}^{n-1} T_{i, J}\right] y\right\} \\
& \quad \leqq\left[1+U_{n, J}\right] D\left\{\left[\prod_{i=1}^{n-1} T_{i, J}\right] x,\left[\prod_{i=1}^{n-1} U_{i, J}\right] y\right\} \leqq \cdots \leqq \prod_{i=1}^{n}\left[1+U_{i, J}\right] D\{x, y\} \\
& \quad \leqq D\{x, y\}\{\exp [U(s, t)]\},
\end{aligned}
$$

as was to be proved.

CoRollary 3. If $t$ is in $Q$ and $s$ between $c$ and $t$, then

$$
Y(t)={ }_{c} \Pi^{t}(T, Y(s)) .
$$

Proof. Suppose $\varepsilon$ is a positive number. There is a chain $J_{1}$ from $c$ to $s$ such that

$$
D\left\{\prod_{J^{\prime} 1}(T, A), Y(s)\right\}<\varepsilon / 2\{\exp [U(c, t)]\}
$$

if $J_{1}^{\prime}$ is a refinement of $J_{1}$. There is a chain $J_{3}$ from $c$ to $t$ having $J_{1}$ as subsequence such that, if $J_{3}^{\prime}$ is a refinement of $J_{3}$,

$$
D\left\{\prod_{J^{\prime}}(T, A), Y(t)\right\}<\varepsilon / 2 \text {. }
$$


Since $s$ is in $Q$ we have $D\left\{\Pi_{J_{1}^{\prime}}(T, A), A\right\} \leqq r$ and therefore $D\{Y(s)$, $A\} \leqq r$. Suppose $J_{3}^{\prime}$ is a refinement of $J_{3}, J_{1}^{\prime}$ the section of $J_{3}^{\prime}$ from $c$ to $s$ and $J_{2}^{\prime}$ the section of $J_{3}^{\prime}$ from $s$ to $t$. Then, by Corollary 2,

$D\left\{\prod_{J^{\prime}}\left(T, \prod_{J_{1}^{\prime}}(T, A)\right), \prod_{J^{\prime}}(T, Y(s))\right\} \leqq D\left\{\prod_{J_{1}^{\prime}}(T, A), Y(s)\right\}\{\exp [U(s, t)]\}<\varepsilon / 2$ that is,

$$
D\left\{\prod_{J_{3}^{\prime}}(T, A), \prod_{J^{\prime}}(T, Y(s))\right\}<\varepsilon / 2 .
$$

Consequently, $D\left\{Y(t), \Pi_{J_{2}^{\prime}}(T, Y(s))\right\}<\varepsilon$ for every refinement $J_{2}^{\prime}$ of the section of $J_{3}$ from $s$ to $t$, that is $Y(t)={ }_{s} \Pi^{t}(T, Y(s))$, as was to be proved.

Corollary 4. Y is continuous.

Proof. If $t$ is in $Q$ and $s$ between $c$ and $t$, then, by Corollaries 1 and 3 we have

$$
D\left\{\Pi^{t}(T, Y(s)), Y(s)\right\} \leqq V(s, t) .
$$

This is true also if $s=c$ or $s=t$. Thus, using Corollary 3 we obtain $D\{Y(t), Y(s)\} \leqq V(s, t)$; and the continuity of $Y$ follows from the continuity of $V$.

Corollary 5. Suppose $J$ is the chain $\left\{s_{i}\right\}_{i=1}^{n+1}$ from $c$ to the number $t$ in $Q, J^{\prime}$ the refinement $\left\{t_{i}\right\}_{i=1}^{m+1}$ of $J, u_{i}$ the integer $K$ such that $s_{i+1}=t_{k+1}$, $\left\{c_{p}\right\}_{p=0}^{n}$ a sequence each term of which is a non-negative number with $c_{0}=0,\left\{A_{i}\right\}_{i=0}^{n}$ a sequence each term of which is a point in $S$ with $A_{0}=A$ and $D\left\{\prod_{J^{\prime}}\left(T, A_{i}\right), A\right\} \leqq r$ for each chain $J^{\prime}$ from $s_{i+1}$ to a number $u$ such that

$$
\begin{aligned}
\left|s_{i+1}-u\right|+\mid u & -t|=| s_{i+1}-t \mid, L_{0}=A, L_{i} \\
= & {\left[\prod_{i=1+u_{i-1}}^{u_{i}} T_{p, J}\right] A_{i-1} \text { and } D\left\{A_{i}, L_{i}\right\} \leqq c_{i}, i=1, \cdots, n . }
\end{aligned}
$$

Then,

$$
D\left\{Y(t), A_{n}\right\} \leqq \sum_{i=1}^{n} c_{i}\left\{\exp \left[U\left(t, s_{i+1}\right)\right]\right\}+\sum_{i=1}^{m} W_{i, J}\left\{\exp \left[U\left(t, t_{i+1}\right)\right]\right\} .
$$

Proof. We shall prove the following statement which implies (2.4): If $J^{\prime \prime}$ is a refinement of $J^{\prime}$, then

$$
\begin{aligned}
D & \left\{\prod_{J^{\prime}}(T, A), A\right\} \leqq \sum_{i=1}^{n} c_{i}\left\{\exp \left[U\left(t, s_{i+1}\right)\right]\right\} \\
& +\sum_{i=1}^{m} W_{i, J}\left\{\exp \left[U\left(t, t_{i+1}\right)\right]\right\} .
\end{aligned}
$$


Suppose $J^{\prime \prime}=\left\{r_{i}\right\}_{i=1}^{j+1}, w_{i}$ is the integer $k$ such that $s_{i+1}=r_{k+1}$ and $M_{i}=\left[\mathrm{I} \int_{p=1}^{w_{i}} T_{p, J^{\prime}}\right] A, i=0, \cdots, n$. Note that $D\left\{M_{i}, A\right\} \leqq r$ and $D\left\{L_{i}, A\right\} \leqq r$, $i=0, \cdots, n$. By an argument similar to that used in proving (2.3) we obtain

$$
D\left\{M_{i}, L_{i}\right\} \leqq D\left\{M_{i-1}, A_{i-1}\right\} \prod_{p=1+u_{i-1}}^{u_{i}}\left[1+U_{p, J}\right]+f_{i}
$$

where

$$
f_{i}=W\left(t_{i+u_{i}}, t_{u_{i}}\right) \text { if } u_{i}=1+u_{i-1},
$$

and

$$
f_{i}=\sum_{q=1+u_{i-1}}^{u_{i}} W_{q, J} \sum_{p=q+1}^{u_{i}}\left[1+U_{p, J}\right] \text { if } u_{i}>1+u_{i-1} .
$$

Thus

$$
D\left\{M_{i}, L_{i}\right\} \leqq D\left\{M_{i-1}, A_{i-1}\right\}\left\{\exp \left[U_{i, J}\right]\right\}+f_{i},
$$

and

$$
\begin{aligned}
& D\left\{M_{i}, A_{i}\right\} \leqq D\left\{M_{i}, L_{i}\right\}+D\left\{L, A_{i}\right\} \\
& \quad \leqq D\left\{M_{i-1}, A_{i-1}\right\}\left\{\exp \left[U_{i, J}\right]\right\}+f_{i}+c_{i},
\end{aligned}
$$

From this inequality and the fact that $M_{n}=\Pi_{J^{\prime \prime}}(T, A)$ we obtain (2.5).

Corollary 6. Suppose $C$ is a point of $S$ and $D\{C, A\}$ is a number $r_{1}$. If $r>r_{1}$ then there is a subinterval $Q_{1}^{\prime}$ of $[a, b]$ containing $c$ such that if $t$ is in $Q_{1}^{\prime}$ and $J$ is a chain from $c$ to $t$ then

$$
D\left\{\Pi_{J}(T, C), A\right\} \leqq r \text { and } D\left\{\Pi_{J}(T, A), A\right\} \leqq r ;
$$

and if $Q_{1}$ is such an interval and $t$ is in $Q_{1}$ then there is a point of $S$ which is the continuous product ${ }_{c} \Pi^{t}(T, C)$. Moreover, if $t$ is in $Q_{1}$ and $J$ is a chain from $c$ to $t$ then

$$
D\left\{\prod_{J}(T, C), Y(t)\right\} \leqq r_{1}\left\{\exp [U(c, t]\}+D\left\{\prod_{J}(T, A), Y(t)\right\} .\right.
$$

Note that if $Q_{1}^{\prime}$ denotes a subinterval $Q_{1}^{\prime \prime}$ of $[a, b]$ containing $c$ such that if $t$ is in $Q_{1}^{\prime \prime}, V(c, t) \leqq r-r_{1}$, then if $t$ is in $Q_{1}^{\prime}$ and $J$ is a chain from $c$ to $t$ we have

$$
D\left\{\prod_{J}(T, C), A\right\} \leqq r \text { and } D\left\{\prod_{J}(T, A), A\right\} \leqq r .
$$

The remainder of the argument is omitted.

3. Specialization. Throughout the rest of this paper, the complete 
metric space $S$ is required to be an additive abelian group with zero element $N$ having a norm $\|\cdot\|$ such that, if $x$ and $y$ are in $S$ then $\|x\|>0$ unless $x=N$ and $\|N\|=0,\|-x\|=\|x\|,\|x+y\| \leqq\|x\|+\|y\|$, $D\{x, y\}=\|x-y\|$. If $F$ is in $B$, the set of all continuous transformations from $S$ into $S$, then $-F$ is the element $G$ of $B$ defined by $G x=$ $-(F x)$ and, if $H$ is in $B$, then $F+H$ is the element $G$ of $B$ defined by $G x=F x+H x$.

Theorem $\mathrm{A}^{\prime}$. Suppose $F$ is a function from the number interval $[a, b]$ into $B, A$ a point of $S, r$ a positive number, $c$ in $[a, b]$, each of $U$ and $V$ a variation function for $[a, b]$. Suppose further that for $p$ and $q$ in $[a, b], x$ and $y$ in $S,\|x-A\| \leqq r$ and $\|y-A\| \leqq r$, we have

(I) $\|[F(p)-F(q)] x-[F(p)-F(q)] y\| \leqq\|x-y\| U(p, q)$

and

(II) $\quad\|[F(p)-F(q)] x\| \leqq V(p, q)$.

If $T$ is the function from the square disc $[a, b] \times[a, b]$ into $B$ defined by $T(p, q)=I+[F(p)-F(q)]$ then there is a subinterval $Q^{\prime}$ of $[a, b]$ containing $c$ such that if $t$ is in $Q^{\prime}$ and $J$ is a chain from $c$ to $t$, then $\left\|\Pi_{\jmath}(T, A)-A\right\| \leqq r$; and, if $Q$ is such an interval and $t$ is in $Q$, then the continuous product ${ }_{c} \Pi^{t}(T, A)$ is a point of $S$.

Proof. We shall prove that $T$ satisfies the hypothesis of Theorem A, with $W$ the closing function $U \cdot V$.

If $x$ and $y$ are in $S, p$ and $q$ are in $[a, b],\|x-A\| \leqq r$ and $\|y-A\| \leqq r$, then

$$
\begin{aligned}
& D\{T(p, q) x, T(p, q) y\}=\|x+[F(p)-F(q)] x-y-[F(p)-F(q)] y\| \\
& \leqq\|x-y\|+\|[F(p)-F(q)] x-[F(p)-F(q)] y\| \\
& \leqq D\{x, y\}[1+U(p, q)],
\end{aligned}
$$

which is (1) of the hypothesis of Theorem A. Also,

$$
D\{T(p, q) x, x\}=\|[F(p)-F(q)] x\| \leqq V(p, q),
$$

which is (2) of the hypothesis of Theorem A.

Suppose $x$ is in $S, p$ and $q$ in $[a, b]$ and $\left\|\Pi_{J^{\prime}}(T, x)-A\right\| \leqq r$ for each chain $J^{\prime}$ from $q$ to a number $t$ in $[a, b]$ such that $|p-t|+|t-q|=$ $|p-q|$. Denote by $\left\{t_{i}\right\}_{i=1}^{n+1}$ a chain $J$ from $p$ to $q$ and set

$$
F\left(t_{i+1}\right)-F\left(t_{i}\right)=\Delta_{i}, x=K_{0} \text { and } K_{i-1}+\Delta_{i} K_{i-1} K_{i}, \quad i=1, \cdots, n .
$$

Then $\left[T_{j, J}\right] x$ is $x$ if $j=0, x+\Delta_{1} x$ if $j=1$ and

$$
x+\sum_{i=1}^{j} \Delta_{i} K_{i-1}=x+\Delta_{1} x+\sum_{i=2}^{j} \Delta_{i}\left[x+\sum_{u=1}^{i-1} \Delta_{u} K_{u-1}\right]=x+\sum_{i=1}^{j} \Delta_{i}\left[\prod_{u=1}^{i-1} T_{u, J}\right] x
$$


if $1<j \leqq n$. Since

$$
T(p, q) x=x+[F(p)-F(q)] x=x+\sum_{i=1}^{n} \Delta_{i} x
$$

we have

$$
\begin{aligned}
& \left\|\left[\prod_{i=1}^{n} T_{i, J}\right] x-T(p, q) x\right\| \\
& =\left\|\left\{+\Delta_{1} x+\sum_{i=2}^{n} \Delta_{i}\left[x+\sum_{u=1}^{i-1} \Delta_{u} K_{u-1}\right]\right\}-\left\{x+\Delta_{1} x+\sum_{i=2}^{n} \Delta_{i} x\right\}\right\| \\
& \quad \leqq \sum_{i=2}^{n}\left\|\Delta_{i}\left[x+\sum_{u=1}^{i-1} \Delta_{u} K_{u-1}\right]-\Delta_{i} x\right\| \leqq \sum_{i=2}^{n} U_{i, J}\left\|\sum_{u=1}^{i-1} \Delta_{u} K_{u-1}\right\| \\
& \quad \leqq \sum_{i=2}^{n} U_{i, J} \sum_{u=1}^{i-1}\left\|\Delta_{u} K_{u-1}\right\| \leqq \sum_{i=2}^{n} U_{i, J} \sum_{u=1}^{i-1} V_{u, J} \\
& \quad \leqq \sum_{i=2}^{n} U_{i, J} V(p, q) \leqq U(p, q) V(p, q)=W(p, q),
\end{aligned}
$$

which is (3) of the hypothesis of Theorem A. This establishes Theorem $\mathrm{A}^{\prime} .^{2}$ As before, we denote ${ }_{c} \Pi^{t}(T, A)$ by $Y(t)$.

CoRollary. If $t$ is in $Q, n$ an integer greater than $1, J$ the chain $\left\{t_{i}\right\}_{i=1}^{n+1}$ from $c$ to $t$ of mesh $\delta$ and $R(\delta)$ is the least number $k$ such that, if each of $p$ and $q$ is in $Q$ and $|p-q| \leqq \delta, V(p, q) \leqq k$, then

$$
\left\|Y(t)-\left[\prod_{i=1}^{n} T_{i, J}\right] A\right\| \leqq R(\delta)\{\exp [U(c, t)]-1\} .
$$

Proof. By (2.3), with $W=U \cdot V$,

$$
\begin{aligned}
\left\|Y(t)-\left[\prod_{i=1}^{n} T_{i, J}\right]\right\| \leqq U_{n, J} V_{n, J}+\sum_{i=2}^{n} U_{i-1, J} V_{i-1, J} \prod_{p=i}^{n}\left[1+U_{p, J}\right] \\
\leqq R(\delta)\left\{U_{n, J}+\sum_{i=2}^{n} U_{i-1, J} \prod_{p=i}^{n}\left[1+U_{p, J}\right]\right\} \\
\leqq R(\delta)\left\{\exp \left[\sum_{i=1}^{n} U_{i, J}\right]-1\right\} \leqq R(\delta)\{\exp [U(c, t)-1\},
\end{aligned}
$$

as was to be proved. ${ }^{3}$

2 Note that if for $V=M U$ some number $M$ then

$$
\sum_{i=2}^{n} U_{i, J} \sum_{u=1}^{i-1} U_{w, J}=M \sum_{i=2}^{n} U_{i, J} \sum_{i=1}^{i-1} U u, J \leqq(M / 2)\left[\sum_{i=1}^{n} U_{i, J}\right]^{2} \leqq(M / 2)[U(p, q)]^{2} \cdot
$$

In this case $W(p, q)$ may be defined to be $(M / 2)[U(p, q)]^{2}$. Note also that if ${ }_{p} \Pi^{q}(T, X)$ exists, then $\left.\left\|{ }_{p} \Pi^{q}(T, X)-T(p, q) x\right\| \leqq(M / 2][U p, q)\right]^{2}$ or $U(p, q) V(p, q)$ depending on whether or not $M$ is a number such that $V=M U$.

${ }^{3}$ If $V=M U$ and $W=(1 / 2) M U^{2}$ then $\left\|Y(t)-\left[\prod_{i=1}^{n} T_{i, J}\right] A\right\| \leqq(1 / 2) R(\delta) \exp [U(c, t)-1]$. 
It follows from this corollary that for a positive number $\varepsilon$ there is a positive number $\delta$ such that, if $t$ is in $Q$ and $J$ a chain from $c$ to $t$ of mesh less that $\delta$ then $\left\|Y(t)-\Pi_{J}(T, A)\right\|<\varepsilon$.

4. Other approximations to $Y(t)$. If $x$ is a positive number and $n$ a positive integer then $\left[1+(x / n)+(1 / 2)(x / n)^{2}\right]^{n}$ is a closer approximation to $e^{x}$ than is $[1+(x / n)]^{n}$. The theorems in this section may be regarded as generalizations of this fact.

With each chain $J$ whose terms are in $[a, b]$ we associate certain elements of $B$ which we denote by the letter $J$ with a subscript and a superscript. Suppose $p$ and $q$ are in $[a, b], J$ the chain $\left\{t_{i}\right\}_{i=1}^{n+1}$ from $p$ to $q$ and $\delta_{i}=F\left(t_{i+1}\right)-F\left(t_{i}\right), i=1, \cdots, n$. Then

$$
J_{0}^{(k)}=J_{i}^{(0)}=I, \quad i=0, \cdots, n, k=1,2,3, \cdots
$$

and

$$
J_{i}^{(k)}=J_{i-1}^{(k)}+\delta_{i} J_{i-1}^{(k-1)}, \quad i=1, \cdots, n, k=1,2,3, \cdots
$$

Thus,

$$
J_{i}^{(k)}=I+\sum_{u=1}^{i} \delta_{u} J_{u-1}^{(k-1)}, \quad i=1, \cdots, n, k=1,2,3, \cdots
$$

Denote by $Q_{1}$ a subinterval of $[a, b]$ containing $c$ such that $V(c, t) \leqq r$ for $t$ in $Q_{1}$.

THEOREM B. If $x$ is in $S, k$ a positive integer, $p$ and $q$ in $Q_{1}$ and $\|x-A\|+V(p, q) \leqq r$, then there is a point $w$ in $S$ such that, for a positive number $\varepsilon$ there is a chain $J$ from $p$ to $q$ such that, if $K$ is a refinement of $J$ and $K=\left\{s_{i}\right\}_{i=1}^{m+1}$ then $\left\|w-K_{m}^{(k)} x\right\|<\varepsilon$.

Proof. To establish the theorem, it suffices to show that, if $J$ is the chain $\left\{t_{i}\right\}_{i=1}^{n+1}$ from $p$ to $q$ of mesh $\delta$ and $K$ the refinement $\left\{s_{i}\right\}_{i=1}^{m+1}$ of $J$, then,

$$
\left\|K_{m}^{(k)} x-J_{n}^{(k)} x\right\| \leqq R(\delta)\{\exp [U(p, q)]-1\} .
$$

For each positive integer $i$ not greater than $n$, denote by $u_{i}$ the integer $u$ such that $t_{i+1}=s_{u+1}$. Suppose $j$ is a positive integer not greater than $n$ and denote by $\left\{q_{u}\right\}_{u=1}^{h+1}$ the section of $J$ from $t_{j}$ to $t_{j+1}$. If $F\left(q_{u+1}\right)-F\left(q_{u}\right)=\delta_{u}, u=1, \cdots, h$, then

$$
J_{j}^{(k)}=J_{j-1}^{(k)}+\left(\sum_{i=1}^{n} \delta_{i}\right) J_{J-1}^{(k-1)}
$$




$$
K_{u_{+u_{j-1}}^{(k)}}^{(k)}=K_{u_{j-1}}^{(k)}+\sum_{i=1}^{u} \delta_{i} K_{1+u_{j-1}}^{(k-1)} \quad u=1, \cdots, h .
$$

Note that $K_{h+u_{j-1}}^{(k)}=K_{u}^{(k)}$. Also, $\left\|K_{i}^{(v)} x-A\right\| \leqq V\left(c, s_{i+1}\right) \leqq r$ and

$$
\begin{aligned}
\left\|J_{u}^{(k)} x-A\right\| \leqq V\left(c, t_{u+1}\right) \leqq r & \\
& i=1, \cdots, m, u=1, \cdots, n, v=1,2,3, \cdots .
\end{aligned}
$$

Then,

$$
\begin{aligned}
\| J_{j}^{(k)} x-K_{u_{j}}^{(k)} & x\|=\|\left\{J_{j-1}^{(k)} x+\sum_{u=1}^{h} \delta_{u} J_{j-1}^{(k-1)} x\right\}-\left\{K_{u_{j-1}}^{(k)} x+\sum_{u=1}^{h} \delta_{u} K_{u-1+u_{j-1}}^{(k-1)} x\right\} \| \\
& \leqq\left\|J_{j-1}^{(k)} x-K_{u_{j-1}}^{(k)} x\right\|+\left\|\sum_{u=1}^{h}\left\{\delta_{u} J_{j-1}^{(k-1)} x-\delta_{u} K_{u-1+u_{j-1}}^{(k-1)} x\right\}\right\| \\
& \leqq\left\|J_{j-1}^{(k)} x-K_{u_{j-1}}^{(k)} x\right\|+\sum_{u=1}^{h}\left\{\left\|\delta_{u} J_{j-1}^{(k-1)} x-\delta_{u} K_{u_{j-1}}^{(k-1)} x\right\|\right. \\
& \left.+\left\|\delta_{u} K_{u_{j-1}}^{(k-1)} x-\delta_{u} K_{u-1+u_{j-1}}^{(k-1)} x\right\|\right\} \leqq\left\|J_{j-1}^{(k)} x-K_{u_{j-1}}^{(k)} x\right\| \\
& +\sum_{u=1}^{h} U\left(q_{u+1}, q_{u}\right)\left\|J_{j-1}^{(k-1)} x-K_{u_{j-1}}^{(k-1} x\right\| \\
& +\sum_{n=1}^{h} U\left(q_{u+1}, q_{u}\right)\left\|K_{u_{j-1}}^{(k-1)} x-K_{u-1+u_{j-1}}^{(k-1)} x\right\| \\
& \leqq\left\|J_{j-1}^{(k)} x-K_{u_{j-1}}^{(k)} x\right\|+\left\|J_{j-1}^{(k-1)} x-K_{u_{j-1}}^{(k-1)} x\right\| U_{j, J}+W_{j, J}
\end{aligned}
$$

where $W=U \cdot V$. An induction argument similar to one used in proving (2.3) now yields

$$
\left\|K_{m}^{(k)} x-J_{n}^{(k)} x\right\| \leqq W_{n, J}+\sum_{i=2}^{n} W_{i, J} \prod_{u=i}^{n}\left[1+U_{u, J}\right] \leqq R(\delta)\{\exp [U(p, q)]-1\},
$$

as was to be proved.

We denote by $T^{(k)}(q, p) x$ the point $w$ of Theorem B. Note that for each refinement $K$ of the chain $J$ of mesh $\delta$ from $p$ to $q$ we have

$$
\left\|T^{(k)}(q, p) x-K_{m}^{(k)} x\right\| \leqq R(\delta)\{\exp [U(p, q)]-1\},
$$

where $m+1$ is the number of terms in $K$.

CoRollary. If $p$ is between $c$ and $q, x$ and $y$ in $S,\|x-A\|+V(p, q) \leqq$ $r,\|y-A\|+V(p, q) \leqq r$ and $J$ is the chain $\left\{t_{i}\right\}_{i=1}^{n+1}$ from $p$ to $q$, then

$$
\left\|J_{n}^{(k)} x-J_{n}^{(k)} y\right\| \leqq\|x-y\|\{\exp [U(p, q)]\}
$$

and, consequently,

$$
\left\|T^{(k)}(q, p) x-T^{(k)}(q, p) y\right\| \leqq\|x-y\|\{\exp [U(p, q)]\} .
$$

Proof. This may be proved by an induction argument similar to one used in proving (2.3), starting with 


$$
\left\|J_{n}^{(k)} x-J_{n}^{(k)} y\right\| \leqq\left\|J_{n-1}^{(k)} x-J_{n-1}^{(k)} y\right\|+V_{n, J}\left\|J_{n-1}^{(k-1)} x-J_{n-1}^{(k-1)} y\right\|
$$

Theorem C. Under the hypothesis of Theorem $B$, if $J$ is the chain $\left\{t_{i}\right\}_{i=1}^{n+1}$ from $p$ to $q$, then

$$
\left\|\left[\prod_{i=1}^{n} T_{i, J}\right] x-J_{n}^{(k)} x\right\| \leqq \frac{1}{k !} V(p, q)[U(p, q)]^{k} .
$$

Proof. As in part of the proof of Theorem $\mathrm{A}^{\prime}$ we have

$$
\left\|\left[\prod_{i=1}^{u} T_{i, J}\right]-J_{u}^{(k)} x\right\| \leqq V\left(p, t_{u+1}\right) U\left(p, t_{u+1}\right), \quad u=1, \cdots, n .
$$

Suppose there is a positive integer $j^{\prime}$ such that, for some positive integer $u$ not greater than $n$ one has

$$
\left\|\left[\prod_{i=1}^{u} T_{i, J}\right]-J_{u}^{\left(j^{\prime}\right)} x\right\|>\frac{1}{j^{\prime} !} V\left(p, t_{u+1}\right)\left[U\left(p, t_{u+1}\right)\right]^{j^{\prime}}
$$

and denote by $j$ the least such positive integer $j^{\prime}$. Then,

$$
\left\|\left[\prod_{i=1}^{u} T_{i, J}\right] x-J_{u}^{(j-1)} x\right\| \leqq \frac{1}{(j-1) !} V\left(p, t_{u+1}\right)\left[U\left(p, t_{u+1}\right)\right]^{\jmath-1}, \quad u=1, \cdots, n .
$$

Since $\quad J_{u}^{(j)} x=x+\sum_{i=1}^{u} \Delta_{i} J_{u-1}^{(j-1)} x, u=1, \cdots, n$,

$$
\begin{aligned}
& \left.\| \prod_{i=1}^{u} T_{i, J}\right] x-J_{u}^{(j)} x\|=\| \sum_{i=1}^{n} \Delta_{i}\left[\prod_{v=1}^{i-1} T_{v, J}\right] x-\sum_{i=1}^{n} \Delta_{i} J_{i-1}^{(j-1)} x \| \\
& \quad \leqq \sum_{i=1}^{u}\left\|\Delta_{i}\left[\prod_{v=1}^{i-1} T_{v, J}\right] x-\Delta_{i} J_{i-1}^{(j-1)} x\right\| \\
& \quad \leqq \sum_{i=1}^{u} U_{i, J} V\left(p, t_{i}\right) \frac{1}{(j-1) !}\left[U\left(p, t_{i}\right)\right]^{j-1} \\
& \quad \leqq V\left(p, t_{u+1}\right) \sum_{i=1}^{u} U_{i, J} \frac{1}{(j-1) !}\left[U\left(p, t_{i}\right)\right]^{j-1} \\
& \quad \leqq V\left(p, t_{u+1}\right) \frac{1}{(j-1) !} \int_{p}^{t_{u+1}}[U(p, r)]^{j-1} d[U(p, r)] \\
& \quad=\frac{1}{j !} V\left(p, t_{u+1}\right)\left[U\left(p, t_{u+1}\right)\right]^{j}, \quad u=1, \cdots, n .
\end{aligned}
$$

which is a contradiction; and Theorem $\mathrm{C}$ is established."

Theorem D. If $J$ is the chain $\left\{t_{i}\right\}_{i=1}^{n+1}$ from $c$ to the number $t$ in $Q$

${ }^{4}$ If $V=M U$ then the inequality in the theorem may be replaced by $\left\|\left[\Pi_{i=1}^{n} T_{i, j}\right] A\right\|$ $\leqq[M /(k+1) !][U(p, q)]^{k+1}$ as the right hand side of the first inequality in the proof may then be $(M / 2)\left[U\left(p, t_{u+1}\right)\right]^{2}$, the left hand side of the second inequality may be $[M /(j+1) !]$ $\left[U\left(p, t_{u+1}\right)\right]^{j+1}$ and so forth with the argument proceeding as before. 
and $k$ a positive integer, then

$$
\left\|Y(t)-\left[\prod_{i=1}^{n} T_{i, J}^{(k)}\right] A\right\| \leqq(1 / k !) \sum_{i=1}^{n} V_{i, J}\left[U_{i, J}\right]^{k}\left\{\exp \left[U\left(t, t_{i+1}\right)\right]\right\} .^{5}
$$

Proof. Denote by $H$ a refinement of $J$ of mesh $\delta$ and let $H_{i}=$ $\left\{q_{u}^{(i)}\right\}_{u=1}^{1+n_{i}}$ be the section of $H$ from $t_{i}$ to $t_{i+1}$. If $K_{i}=\left[H_{i}\right]_{n_{i}}^{(k)}, i=1, \cdots, n$, then, by Theorem $\mathrm{C}$,

$$
\left\|K_{j}\left[\prod^{j-1} K_{i}\right] A-\prod_{u=1}^{n_{i}} T_{u H_{j}}\left[\prod_{i=1}^{j-1} K_{i}\right] A\right\| \leqq[1 / k !] V_{j, J}\left[U_{j, J}\right]^{k}, \quad j=1, \cdots, n .
$$

From Corollary 5 to Theorem $\mathrm{A}$ and the corollary to Theorem $\mathrm{A}^{\prime}$ it follows that

$$
\begin{aligned}
\left\|Y(t)-\left[\prod_{i=1}^{n} K_{i}\right] A\right\| \leqq & R(\delta)\{\exp [U(c, t)]-1\} \\
& +[1 / k !] \sum_{i=1}^{n} V_{i, J}\left[U_{i, J}\right]^{k}\left\{\exp \left[U\left(t, t_{i+1}\right)\right]\right\} .
\end{aligned}
$$

By (4.1) and the corollary to Theorem B we have

$$
\begin{aligned}
& \left\|\left[\prod_{i=1}^{j} K_{i}\right] A-\left[\prod_{i=1}^{j} T_{i, J}^{(k)}\right] A\right\|=\left\|K_{j}\left[\prod_{i=1}^{j-1} K_{i}\right] A-T_{j, J}^{(k)}\left[\prod_{i=1}^{j-1} T_{i, J}^{(k)}\right] A\right\| \\
& \leqq\left\|K_{\mathfrak{j}}\left[\prod_{i=1}^{j-1} K_{i}\right] A-T_{j, J}^{(k)}\left[\prod_{i=1}^{j-1} K_{i}\right] A\right\|+\left\|T_{j, J}^{(k)}\left[\prod_{i=1}^{j-1} K_{i}\right] A-T_{j, J}^{(k)}\left[\prod_{i=1}^{j-1} T_{i, J}^{(k)}\right] A\right\| \\
& \leqq R(\delta)\left\{\exp \left[U_{j, J}\right]-1\right\}+\left\{\exp \left[U_{j, J}\right]\right\}\left\|\left[\prod_{i=1}^{j-1} K_{i}\right] A-\left[\prod_{i=1}^{j-1} T_{i, J}^{(k)}\right] A\right\|, \\
& j=1, \cdots, n ;
\end{aligned}
$$

and, by mathematical induction,

$$
\begin{aligned}
\left\|\left[\prod_{i=1}^{n} K_{i}\right] A-\left[\prod_{i=1}^{n} T_{i, J}^{(k)}\right] A\right\| & \leqq R(\delta) \sum_{i=1}^{n}\left\{\exp \left[U_{i, J}\right]-1\right\}\left\{\exp \left[U\left(t, t_{i+1}\right)\right]\right\} \\
& =R(\delta)\{\exp [U(t, c)]-1\} .
\end{aligned}
$$

Thus,

$$
\begin{aligned}
\left\|Y(t)-\left[\prod_{i=1}^{n} T_{i, J}^{(k)}\right] A\right\| & \leqq 2 R(\delta)\{\exp [U(c, t)]-1\} \\
& +[1 / k !] \sum_{i=1}^{n} V_{i, J}\left[U_{i, J}\right]^{k}\left\{\exp \left[U\left(t, t_{i+1}\right)\right]\right\}
\end{aligned}
$$

for every refinement $H$ of $J$, that is for every positive number $\delta$. This establishes the theorem.

Note that, in the case $n=1$ and $J$ is the two-term sequence $c, t$, the sequence $\left\{T^{(i)}(t, c) A\right\}_{i=1}^{\infty}$ converges to $Y(t)$.

5 If $V=M U$ then the inequality in the theorem may be

$$
\left\|Y(t)-\left[\prod_{i=1}^{n} T_{i, J}^{(k)}\right] A\right\| \leqq[M /(k+1) !] \sum_{i=1}^{n}\left[U_{i, J}\right]^{k+1}\left\{\exp \left[U\left(t_{1}, t_{i+1}\right)\right]\right\} .
$$


5. The integral equation $Y(t)=A+\int_{c}^{t} d F \cdot Y$. In this section we shall prove that, under the hypothesis of Theorem $\mathrm{A}^{\prime}$, the only solution $Y(t)$ on $Q$ of this integral equation, which is continuous and satisfies $\|Y(t)-A\| \leqq r$, is ${ }_{c} \Pi^{t}(T, A)$. We first make precise the meaning of the integral.

The statement that $\left\{a_{\iota}\right\}_{i=1}^{n+1}$ is a subdivision from the number $u$ to the number $v$ means that $\left\{a_{i}\right\}_{i=1}^{n+1}$ is a non-increasing or non-decreasing sequence having an odd number of terms such that $\left\{a_{2 i-1}\right\}_{i=1}^{(n+2) / 2}$ is a chain from $u$ to $v$; the mesh of the subdivision is the mesh of this chain ; and a refinement $\left\{b_{i}\right\}_{i=1}^{m+1}$ of $\left\{a_{i}\right\}_{i=1}^{n+1}$ is a subdivision from $u$ to $v$ such that $\left\{b_{2 i-1}\right\}_{i=2}^{(m+2) / 2}$ is a refinement of the chain $\left\{a_{2 i-1}\right\}_{i=1}^{(n+2) / 2}$ from $u$ to $v$. If $F$ is a function from the number interval $[a, b]$ into $B, X$ a function from $[a, b]$ into $S, u$ and $v$ in $[a, b]$ and $R$ the subdivision $\left\{t_{i}\right\}_{i=1}^{2 n+1}$ from $u$ to $v$ then the sum $\sum_{i=1}^{n}\left[F\left(t_{2 i+1}\right)-F\left(t_{2 i-1}\right)\right] X\left(t_{2 i}\right)$ is denoted by $\sum_{R} \Delta F \cdot X$. The statement that $X$ is F-integrable from $u$ to $v$ means there is a point $w$ in $S$ such that for a positive number $\varepsilon$ there is a subdivision $R$ from $u$ to $v$ such that, if $R^{\prime}$ is a refinement of $R$, then $\left\|\sum_{R^{\prime}} \Delta F \cdot X-w\right\|<\varepsilon$. If $X$ is $R$-integrable from $u$ to $v$, this point $w$ is denoted by $\int_{u}^{v} d F \cdot X$.

THEOREM E. If $F$ is a function from the number interval $[a, b]$ into $B, X$ a continuous function from $[a, b]$ into $S, u$ and $v$ in $[a, b]$ and $V$ $a$ variation function for $[a, b]$ such that, for each $p, q$ in $[a, b] \times[a, b]$ and each of $x$ and $y$ in the image of $[a, b]$ under $X$ we have

$$
\|[F(p)-F(q)] x-[F(p)-F(q)] y\| \leqq\|x-y\| V(p, q),
$$

then $X$ is $F$-integrable from $u$ to $v$.

A proof, following closely an existence proof for ordinary integrals, is omitted. (Cf. [2]).

THEOREM F. Under the hypothesis of Theorem $\mathrm{A}^{\prime}$, the function $Y$ from $Q$ into $S$ defined by $Y(t)={ }_{c} \Pi^{t}(T, A)$ is the only continuous function $G$ from $Q$ into $S$ such that, $G(t)=A+\int_{t}^{c} d F \cdot G$ and $\|G(t)-A\| \leqq r$ for $t$ in $Q$.

Proof. The function $Y$ is continuous (Corollary 4 to Theorem A) and $F$-integrable from $c$ to each $t$ in $Q$ (Theorem E). Suppose $\varepsilon$ is a positive number and denote by $\delta$ a positive number such that, if $J$ is a chain from $c$ to the number $t$ in $Q$ of mesh not greater than $\delta$, then

$$
\left\|Y(t)-\prod_{J}(T, A)\right\|<\varepsilon / 3[U(\alpha, \beta)+1],
$$

where $Q=[\alpha, \beta]$ (Corollary to Theorem $\mathrm{A}^{\prime}$ ). Suppose $R$ is a subdivision 
from $c$ to $t$ such that, if $R^{\prime}$ is a refinement of $R$ then

$$
\left\|\sum_{R^{\prime}} \Delta F \cdot Y-\int_{c}^{t} d F \cdot Y\right\|<\varepsilon / 3
$$

and suppose $\left\{s_{t}\right\}_{i=1}^{2 n+1}$ is a refinement $R^{\prime}$ of $R$ of mesh not greater than $\delta$ such that $s_{2 i-1}=s_{2 i}, i=1, \cdots, n$. If $\Delta_{i}=F\left(s_{2 i+1}\right)-F\left(s_{2 i-1}\right)$, which is $T_{2 i, R^{\prime}}-I, i=1, \cdots, n$, then

$$
\begin{aligned}
& \left\|Y(t)-\left[A+\int_{c}^{t} d F \cdot Y\right]\right\| \\
& \quad \leqq Y Y(t)-\left\{A+\sum_{i=1}^{n}\left[T_{2 i, R^{\prime}}-I\right]\left[\prod_{j=1}^{-1} T_{2 j, R^{\prime}}\right] A\right\} \| \\
& +\left\|\sum_{i=1}^{n} \Delta_{i}\left[\prod_{j=1}^{i-1} T_{2 j, R^{\prime}}\right] A-\sum_{i=1}^{n} \Delta_{i} Y\left(s_{2 i-1}\right)\right\|+\left\|\sum_{i=1}^{n} \Delta_{i} Y\left(s_{2 i}\right)-\int_{c}^{t} d F \cdot Y\right\| \\
& \quad \leqq\left\|Y(t)-\left[\prod_{j=1}^{n} T_{2 i, R^{\prime}}\right] A\right\|+\sum_{i=1}^{n} U_{2 i, R^{\prime}}\left\|\left[\prod_{j=1}^{i-1} T_{2 j, R^{\prime}}\right] A-Y\left(s_{2 i-1}\right)\right\| \\
& \quad+\varepsilon / 3<\varepsilon .
\end{aligned}
$$

Therefore, $\left\|Y(t)-\left[A+\int_{c}^{t} d F \cdot Y\right]\right\|=0$ so that $Y(t)=A+\int_{c}^{t} d F \cdot Y$.

Suppose that $G$ is a continuous function from $Q$ into $S$ such that $\|G(t)-A\| \leqq r$ and $G(t)=A+\int_{c}^{t} d F \cdot G$ for each $t$ in $Q$. From the definitions of the integrals involved, we have that if $k$ is the continuous function such that $\|Y(t)-G(t)\|=k(t)$ for each $t$ in $Q$ and $g(t)=$ $U(c, t)$ for each $t$ in $Q$, then

$$
\left\|\int_{c}^{t} d F \cdot Y-\int_{c}^{t} d F \cdot G\right\| \leqq \int_{c}^{t} d g \cdot k
$$

for each $t$ in $Q$.

Since

$$
\|Y(t)-G(t)\|=\left\|\int_{c}^{t} d F \cdot Y-\int_{c}^{t} d F \cdot G\right\|
$$

it follows that $0 \leqq k(t) \leqq \int_{c}^{t} d g \cdot k$ for each $t$ in $Q$. But this implies that $k(t)=0$ and hence, $F(t)=G(t)$ for each $t$ in $Q$. This completes the proof of Theorem F.

6. Examples. In this section some of the results of the preceding sections are applied.

Example 1. Suppose $F$ is a function from $[a, b]$ into $B$ such that $F(t)[x+y]=F(t) x+F(t) y$ for all $t$ in $[a, b]$ and all $x$ and $y$ in $S$. Suppose furthermore that $A$ is in $S, c$ is in $[a, b], T(p, q)=I+F(p)-$ $F(q)$ and there is a variation function $U$ for $[a, b]$ such that

$$
\|[F(q)-F(p)] x\| \leqq U(p, q)\|x\|
$$


for every $x$ in $S$ and each $(p, q)$ in $[a, b] \times[a, b]$.

That Theorem $\mathrm{A}^{\prime}$ implies that ${ }_{c} \Pi^{t}(T, A)$ exists for each $t$ in $[a, b]$ can be seen from the following. Suppose $t^{\prime}$ is in $[a, b]$. Denote $\|A\|\left\{\exp \left[U\left(c, t^{\prime}\right)\right]\right\} U(p, q)$ by $V(p, q)$ for each $(p, q)$ in $[a, b] \times[a, b]$. Denote by $r$ a positive number not less than $\|A\|\left\{\exp \left[U\left(c, t^{\prime}\right)\right]-1\right\}$. The reader may verify that (I) and (II) of the hypothesis of Theorem $\mathrm{A}^{\prime}$ are satisfied for $\|x-A\| \leqq r$ and $\|y-A\| \leqq r$. Suppose $J$ is the chain $\left\{t_{i}\right\}_{i=1}^{n+1}$ from $c$ to a number $t^{\prime \prime}$ such that $\left|t^{\prime}-t^{\prime \prime}\right|+\left|t^{\prime \prime}-c\right|=$ $\left|t^{\prime}-c\right|$. Since

$$
\begin{aligned}
& \left\|\left[\prod_{i=1}^{k} T_{j, J}\right] A\right\| \leqq A \|\left\{\prod_{j=1}^{k}\left[1+U_{j, J}\right]\right\}, \quad k=1, \cdots, n, \\
& \left\|\left[\prod_{i=1}^{n} T_{i, J}\right] A-A\right\|=\sum_{i=1}^{n}\left[F\left(t_{i+1}\right)-F\left(t_{i}\right)\right]\left[\prod_{j=1}^{i-1} T_{j, J}\right] A \| \\
& \leqq \sum_{i=1}^{n} V_{i, J}\left\|\left[\prod_{j=1}^{i-1} T_{j, J}\right] A\right\| \leqq \sum_{i=1}^{n} V_{i, J} \prod_{j=1}^{i-1}\left[1+V_{j, J}\right]\|A\| \\
& \quad \leqq\|A\|\left\{\exp \left[\sum_{i=1}^{n} U_{i, J}\right]-1\right\} \leqq\|A\|\left\{\exp \left[U\left(t, t^{\prime}\right)\right]-1\right\} \leqq r .
\end{aligned}
$$

Thus, according to Theorem $\mathrm{A}^{\prime}{ }_{c} \Pi^{t^{\prime}}(T, A)$ is a point of $S$.

If $J$ has mesh $\delta$, then by the corollary to Theorem $\mathrm{A}^{\prime}$ (see footnote 3) we have

$$
\left\|_{c} \Pi^{t^{\prime}}(T, A)-\prod_{J}(T, A)\right\| \leqq(1 / 2) R(\delta) \exp \left[U\left(c, t^{\prime}\right)-1\right],
$$

where $R(\delta)$ is as defined in that corollary. But since $V=\|A\|\left\{\exp \left[U\left(c, t^{\prime}\right)\right]\right\} U$, we have

$$
R(\delta)=\|A\|\left\{\exp \left[U\left(c, t^{\prime}\right)\right]\right\} R^{\prime}(\delta)
$$

where $R^{\prime}(\delta)$ is the least number $k$ such that if $p$ and $q$ are in $[a, b]$ and $|p-q| \leqq \delta$ then $U(p, q) \leqq k$.

Thus,

$\left\|_{c} \Pi^{t^{\prime}}(T, A)-\prod_{J}(T, A)\right\| \leqq \frac{1}{2}\|A\|\left\{\exp \left[U\left(c, t^{\prime}\right)\right]\right\} R^{\prime}(\delta)\left\{\exp \left[U\left(c, t^{\prime}\right)-1\right\}\right.$.

A smaller upper bound to the error in approximating ${ }_{c} \prod^{t^{\prime}}(T, A)$ by $\Pi_{J}(T, A)$ can be found by the use of Corollary 6 to Theorem A. This is done by redefining $V$. Suppose $t^{\prime} \neq c$.

Denote $\left[\Pi_{i=1}^{j} T_{i, J}\right] A$ by $c_{j}$ and $\left\|c_{j}-{ }_{c} \Pi^{t_{j+1}}(T, A)\right\|$ by $r_{j}, j=0,1 \cdots, n$. Note that

$\left\|c_{j}\right\| \leqq\|A\| \exp \left[U\left(c, t_{j+1}\right)\right]$ and $\left\|_{c} \Pi^{t_{j+1}}(T, A)\right\| \leqq\|A\| \exp \left[U\left(c, t_{j+1}\right)\right]$,

$$
i=0,1, \cdots, n \text {. }
$$

Denote by $R_{j}$ the interval with end points $t_{j}$ and $t_{j+1}$ and by $V$ a variation function for $[a, b]$ such that

$$
V(p, q)=\exp \left[U\left(c, t_{j+1}\right)\right] U(p, q)
$$


for $(p, q)$ in $R_{j} \times R_{j}, j=1, \cdots, n$. Taking into account the last comment in footnote 2 and Corollaries 3 and 6 to Theorem A we have

$$
\begin{aligned}
& \left\|\left[\prod_{i=1}^{j} T_{i, J}\right] A-{ }_{c} \Pi^{t_{j+1}}(T, A)\right\|=\left\|T_{j, J} c_{j-1}-{ }_{t_{j}} \Pi^{t_{j+1}}\left(T,{ }_{c} \Pi^{t_{j}}(t, A)\right)\right\| \\
& \quad \leqq r_{j} \exp \left[U_{j, J}\right]+\left\{\exp \left[U\left(c, t_{j+1}\right)\right]\right\}\left\{\left[U_{j, J}\right]^{3} / 2\right\} \\
& =\left\|c_{j-1}-{ }_{c} \Pi^{t_{j}}(T, A)\right\|\left\{\exp \left[U_{j, J}\right]\right\}+\left\{\exp \left[U\left(c, t_{j+1}\right)\right]\right\}\left\{\left[U_{j, J}\right]^{2} / 2\right\}, \\
& j=1, \cdots, n .
\end{aligned}
$$

By mathematical induction,

$$
\left\|\left[\prod_{i=1}^{n} T_{i, J}\right] A-{ }_{c} \Pi^{t^{\prime}}(T, A)\right\| \leqq\|A\|\left\{\exp \left[U\left(c, t^{\prime}\right)\right]\right\} \sum_{i=1}^{n}\left\{\left[U_{i . J}\right]^{2} / 2\right\} \text {. }
$$

This may be compared with the upper bound to the error found by MacNerney [2] which is, in the notation of this paper,

$$
\|A\|\left\{\exp \left[U\left(c, t^{\prime}\right)\right]\right\} \sum_{i=1}^{n}\left|\exp \left[U_{i, J}\right]-1\right| U_{i, J} .
$$

Some additional implications of this specialization of $F$ will be stated without proof. Suppose that $(p, q)$ is in $[a, b] \times[a, b], x$ in $S, n$ a positive integer greater than $3, K$ the chain $\{\mathbf{s}\}_{i=1}^{m+1}$ from $p$ to $q, r$ a positive number and $U(p, q)[\|x\|+r] \leqq r$. Then, by Theorem $\mathrm{B}, T^{(k)}(p, q) x$ is a point of $S$ for each positive integer $k$. If $\Delta_{\iota}=F\left(s_{i+1}\right)-F\left(s_{i}\right), i=1, \cdots, n$, then

$$
K_{j}^{(1)}=I+\left(\Delta_{1}+\cdots+\Delta_{j}\right)
$$

and

$$
\begin{aligned}
& K_{j}^{(2)}=I+\Delta_{1}+\Delta_{2}\left[I+\Delta_{1}\right]+\Delta_{3}\left[I+\left(\Delta_{1}+\Delta_{2}\right)\right]+\cdots \\
& +\Delta_{j}\left[I+\left(\Delta_{1}+\cdots+\Delta_{j-1}\right)\right] \\
& =I+\left(\Delta_{1}+\cdots+\Delta_{j}\right)+\left[\Delta_{2} \Delta_{1}+\left(\Delta_{3} \Delta_{1}+\Delta_{3} \Delta_{2}\right)+\cdots\right. \\
& \left.+\left(\Delta_{j} \Delta_{1}+\cdots+\Delta_{j} \Delta_{j}^{-}{ }_{1}\right)\right], \\
& j=3, \cdots, n \text { and so on for } k=3,4, \cdots \text {. }
\end{aligned}
$$

Moreover, if $I_{1}(p, q) y=[F(p)-F(q)] y$ and

$$
I_{j+1}(p, q) y=\int_{p}^{q} d F(w) \cdot I_{j}(w, q) y, \quad j=1,2, \cdots,
$$

for each number pair $(p, q)$ in $[a, b] \times[a, b]$ and all $y$ in $S$, then $T^{(k)}(p, q) x=x+I_{1}(p, q) x+\cdots+I_{k}(p, q) x$. [2], [9]

If $S$ is a normed, linear and complete space, and $F(p) F(q)=$ $F(q) F(p)$ for each $(p, q)$ in $[a, b] \times[a, b]$, then $I_{j}(p, q) x=[1 / j !][F(p)-$ $F(q)]^{j} x$. [4]

Example 2. For this example, $S$ is the real numbers. It is shown how a solution to 


$$
Y(t)=A+\int_{c}^{t} f[u, Y(u)] d u
$$

can be obtained by means of the continuous product under certain condition on $f$.

THEOREM G. Suppose that $[a, b]$ is a number interval, $c$ in $[a, b]$, $A$ a number, $r$ a positive number and $f$ a function from the number plane into the numbers such that if $x$ is a number then the function $g$ defined by $g(t)=f(t, x)$ for each number $t$ is quasi-continuous and the function $h$ defined by $h(t)=f(x, t)$ for each number $t$ is continuous. If there is a variation function $U$ for $[a, b]$ such that

$$
\left|\int_{p}^{q}[f(v, x)-f(v, y)] d v\right| \leqq|x-y| U(p, q)
$$

for each $(p, q)$ in $[a, b] \times[a, b],|x-A| \leqq r$ and $|y-A| \leqq r$, then is $a$ subinterval $Q_{1}$ of $[a, b]$ containing $c$ such that there is only one continuous function $Y$ from $Q_{1}$ into the numbers such that $Y(t)=A+\int_{c}^{t} f[u, Y(u)] d u$ and $|Y(t)-A| \leqq r$.

Proof. Denote $\int_{c}^{u} f[v, x] d v$ by $F(u) x$ for each number $x$ and each $u$ in $[a, b]$, and denote $I+F(p)-F(q)$ by $T(p, q)$ for each $(p, q)$ in $[a, b] \times[a, b]$. Then,

$$
\begin{aligned}
& \|[F(q)-F(p)] x-[F(q)-F(p)] y\| \\
& \quad=\left|\int_{p}^{q}[f(v, x)-f(v, y)] d v\right| \leqq|x-y| U(p, q) .
\end{aligned}
$$

Denote by $M$ a number such that $M \geqq|f(v, x)|$ if $v$ is in $[a, b]$ and $|x-A| \leqq r$. Thus, if $V(q, p)=|q-p| M$, then

$$
|[F(q)-F(p)] x|=\left|\int_{p}^{q} f(v, x) d v\right| \leqq|q-p| M
$$

for $(p, q)$ in $[a, b] \times[a, b]$ and $|x-A| \leqq r$. As in (i) in the proof of Theorem A, denote by $Q_{1}$ a subinterval of $[a, b]$ containing $c$ such that $V(c, t) \leqq r$ for $t$ in $Q_{1}$.

If $Y(t)={ }_{c} \Pi^{t}(T, A)$ for each $t$ in $Q_{1}$, then $Y$ is the only continuous function from $Q_{1}$ into the numbers so that $Y(t)=A+\int_{c}^{t} d F \cdot Y$ and $|Y(t)-A| \leqq r$ for each $t$ in $Q_{1}$. Using the definition of $F$ and several elementary properties of integrals one can see that

$$
\int_{c}^{t} d F \cdot Y=\int_{c}^{t} f[u, Y(u)] d u \text { for each } t \text { in } Q_{1} .
$$

This establishes the theorem. 
ExAmple 3. The above example may be extended to the system of equations

$$
Y_{\alpha}(t)=A_{\alpha}+\int_{c}^{t} f_{\alpha}\left[u, Y_{1}, \cdots, Y_{n}(u)\right] d u, \quad i=1, \cdots, n
$$

where the $f_{\alpha}$ satisfy suitable conditions. This system of equations may be written as

$$
Y(t)=A+\int_{c}^{t} d F Y
$$

where

$$
Y(t)=\left[Y_{\alpha}(t)\right], A=\left[A_{\alpha}\right] \text { and } F(u)\left[X_{\alpha}\right]=\left[\int_{c}^{t} f_{\alpha}\left[v, x_{1}, \cdots, x_{n}\right] d v\right]
$$

for each number $u$ and each point $\left[X_{\alpha}\right], \alpha=1, \cdots, n$.

EXAMPlE 4. The integral equation

$$
Y(x)=x+\int_{0}^{x} Y(u)^{2} d u,
$$

which is a special case of (6.2) has $Y(x)=\tan x$ as a solution. This equation can be written $Y(x)=\int_{0}^{x} d F \cdot Y$, where $F(u) y=u\left(1+y^{2}\right)$ for all numbers $u$ and $y$.

This integral equation will be considered in some detail in order to illustrate how Theorem $\mathrm{F}$ and various of the other theorems and corollaries of this paper may be applied.

Suppose that $r$ is a positive number. If $p, q, y$ and $z$ are numbers, $|y| \leqq r$ and $\mid z) \leqq r$, then

$$
\begin{aligned}
|[F(p)-F(q)] y|= & \left|p\left(1+y^{2}\right)-q\left(1+y^{2}\right)\right| \\
& =\left|(p-q)\left(1+y^{2}\right)\right| \leqq|p-q|\left(1+r^{2}\right)=V(p, q)
\end{aligned}
$$

and

$$
\begin{aligned}
\mid[F(p)- & F(q)] y-[F(p)-F(q)] x \mid \\
& =\left|(p-q)\left(y^{2}-z^{2}\right)\right|<|p-q|(2 r)|y-z|=U(p, q)|y-z|,
\end{aligned}
$$

where $U(p, q)=2 r|p-q|$ and $V(p, q)=\left(1+r^{2}\right)|p-q|$ for each number pair $(p, q)$.

Now the contraction of $U$ and $V$ to an interval is a variation function on that interval. Suppose that

$$
T(p, q) y=y+[F(p)-F(q)] y=y+(p-q)\left(1+y^{2}\right)
$$

for each of $p, q, y$ a number.

According to (i) of the proof of Theorem $\mathrm{A},{ }_{0} \Pi^{x}(T, 0)$ exists if 


$$
V(x, 0)=\left(1+r^{2}\right)|x| \leqq r \text {, that is if }|x| \leqq r /\left(1+r^{2}\right) .
$$

Thus (6.4) determines (see (i) of the proof of Theorem A) an interval of convergence for the continuous product for each positive number $r$. The longest such interval determined by $(6.4)$ is $[-1 / 2,1 / 2]$ as $1 / 2$ is the maximum of $r /\left(1+r^{2}\right)$ for all positive numbers $r$.

Suppose that $0<|x|<1 / 2$. Since $(1 / 2)|x|-\sqrt{1 /(2|x|)^{2}-1}$ is the least number $t$ such that $|x| \leqq t /\left(1+t^{2}\right)$, the choice $r_{1}=1 / 2|x|-$ $\sqrt{1 /(2|x|)^{2}-1}$ and $V(p, q)=\left(1+r_{1}^{2}\right)|p-q|$ for each number pair $(p, q)$ will yield, for each chain $J$ from 0 to $x$, the smallest upper bound to ${ }_{0} \Pi^{x}(T, 0)-\Pi_{J}(T, 0) \mid$ of the type given in the corollary to Theorem $\mathrm{A}^{\prime}$. By means of (6.4) this yields an interval of convergence containing $x$.

Suppose that $C, r_{2}$ and $r_{3}$ are numbers such that $|Y(1 / 2)-C|=$ $r_{2}<r_{3}$. Suppose furthermore that $|C|+r_{3}=r_{4}, U(p, q)=2 r_{4}|p-q|$ and $V(p, q)=\left(1+r_{4}^{2}\right)|p-q|$ for each number pair $(p, q)$. Thus, by Corollary 6 to Theorem A, if $Q_{1}$ is an interval such that $V\left(1 / 2, x_{1}\right) \leqq$ $r_{3}-r_{2}$ if $x_{1}$ is in $Q_{1}$, then there is a point which is ${ }_{1 / 2} \Pi^{x, 1}(T, C)$ for each $x_{1}$ in $Q_{1}$.

Suppose that $x_{2}$ is in $Q_{1}$ and is greater than $1 / 2$ and $J$ is a chain from $1 / 2$ to $x_{2}$. From the inequalities in Corollary 6 to Theorem A and the corollary to Theorem A, the error in approximating $Y\left(x_{2}\right)$ (i.e., $\tan$ $x)$ by $\Pi_{J}(T, C)$ can be determined. From these corollaries, it follows that for a positive number $\varepsilon$ there is a positive number $\delta$ and a chain $J$ from $1 / 2$ to $x_{2}$ such that, if $\left|\tan 1 / 2-C_{1}\right|<\delta$ and $J^{\prime}$ is a refinement of $J$, then $\left|\Pi_{J^{\prime}}\left(T, C_{1}\right)-\tan x\right|<\varepsilon$.

In this way, the interval of convergence of the continuous product can be extended beyond $[-1 / 2,1 / 2]$.

Suppose that $q$ is in $[-1 / 2,1 / 2], p$ is between 0 and $q$ and $x$ is a number such that $|x|+2|q-p| \leqq 1$. As an illustration for $\S 4$ it will now be shown how $T^{(2)}(p, q) x$ can be determined where $T(u, v) y=$ $y+(u-v)\left(1+y^{2}\right)$ for each number pair and every number $y$.

By Theorem B, there is a number which is $T^{(2)}(p, q) x$. Suppose that $n$ is a positive integer greater than 2 . Denote by $J_{n}$ the chain from $p$ to $q$ which is $\{p+(i-1)(q-p) / n\}_{i=1}^{n+1}$. Denote

$$
F[p+i(q-p) / n]-F[p+(i-1)(p-q) / n] \text { by } \Delta_{i}, \quad j=1, \cdots, n .
$$

Using the notation of $\S 4$ we have

$$
\begin{array}{ll}
{\left[J_{n}\right]_{u}^{(1)} x=x+\left(\Delta_{1}+\cdots+\Lambda_{n}\right) x} & \\
\quad=x+[u(q-p) / n]\left(1+x^{2}\right), & u=0,1, \cdots, n, \\
{\left[J_{n}\right]_{1}^{(2)}=\left[J_{n}\right]_{0}^{(2)}+\Delta_{1}\left[J_{n}\right]_{1}^{(1)}=I+\Delta_{1},} & \\
{\left[J_{n}\right]_{i}^{(2)}=I+\Delta_{1}+\Delta_{i}\left[I+\Delta_{1}\right]+\Delta_{3}\left[I+\left(\Delta_{1}+\Delta_{2}\right)\right]} & \\
\quad+\cdots+\Delta_{i}\left[I+\left(\Delta_{1}+\cdots+\Delta_{i-1}\right)\right], & j=3, \cdots, n .
\end{array}
$$


So,

$$
\begin{aligned}
{\left[J_{n}\right]_{n}^{(2)} x } & =x+\Delta_{1} x+\sum_{i=1}^{n} \Delta_{i}\left[x+\left(\sum_{u=1}^{i-1} \Delta_{u}\right) x\right] \\
& =x+[(q-p) / n] \sum_{i=1}^{n}\left\{1+\left[x+(q-p)(i-1)\left(1+x^{2}\right) / n\right]^{2}\right\} \\
& =x+(q-p)\left(1+x^{2}\right)+2 x\left(1+x^{2}\right)[(q-p) / n]^{2}[n(n-1) / 2] \\
& +\left(1+x^{2}\right)^{2}[(q-p) / n]^{3}[(n-1)(2 n-1) n / 6] .
\end{aligned}
$$

As $n \rightarrow \infty$ we get

$$
\begin{aligned}
{\left[J_{n}\right]_{n}^{(2)} x \rightarrow x+(q-p)\left(1+x^{2}\right) } & +x\left(1+x^{2}\right)(q-p)^{2} \\
& +(1 / 3)\left(1+x^{2}\right)^{2}(q-p)^{3}=T^{(2)}(p, q) x .
\end{aligned}
$$

The reader may note that the first three terms of $T^{(2)}(p, q) x$ are the same as the first three terms of the power series expansion about $p$ of $Y(q)$ where $Y$ is the function satisfying

$$
Y(t)=(t-p)+x+\int_{p}^{t} Y(u)^{2} d u
$$

for each number $t$ such that $|p-t|+|t-q|=|p-q|$.

\section{REFERENCES}

1. Garrett Birkoff, On product integration, J. Math. Phys. 16 (1937), 104-132.

2. J. S. MacNerney, Stieltjes integrals in linear spaces, Ann. of Math. 61 (1955), 354367.

3. _ Continuous products in linear spaces, J. Elisha Mitchell Sci. Soc. 71 (1955), 185-200.

4. P. R. Masani, Multiplicative Riemann integration in normed rings, Trans. Amer. Math. Soc. 61 (1947), 147-192.

5. G. Rasch, Zur Theorie und Anwendung des Produktintegrals, J. Reine Angew. Math. 171 (1934), 65-119.

6. L. Schlesinger, Neue Grundlagen für einen Infinitesimalkalkül der Matrizen, Math. Z. 33 (1931), 33-61.

7. F. M. Stewart Integration in noncommutative spaces, Trans. Amer. Math. Soc. 68 (1950), 76-104.

8. V. Volterra, Sulle equazioni differenziali lineari, Rend. Accade. die Lincei (4) 3, (1887), 393-396.

9. H. S. Wall, Concerning harmonic mairices, Arch. Math. 5 (1954), 160-167.

The UNIVERsity of TeXAS AND

The Illinois Institute of TeChNology 



\section{PACIFIC JOURNAL OF MATHEMATICS}

\section{EDITORS}

David Gilbarg

Stanford University

Stanford, California

R. A. Beaumont

University of Washington

Seattle 5, Washington

\author{
A. L. Whiteman
}

University of Southern California

Los Angeles 7, California

E. G. Straus

University of California

Los Angeles 24, California

\section{ASSOCIATE EDITORS}

\author{
E. F. BECKENBACH \\ C. E. BURGESS \\ M. HALL \\ E. HEWITT
}

\author{
A. HORN \\ V. GANAPATHY IYER \\ R. D. JAMES \\ M. S. KNEBELMAN
}

L. NACHBIN
I. NIVEN
T. G. OSTROM
H. L. ROYDEN

M. M. SCHIFFER

G. SZEKERES

F. WOLF

K. YOSIDA

\section{SUPPORTING INSTITUTIONS}

\author{
UNIVERSITY OF BRITISH COLUMBIA \\ CALIFORNIA INSTITUTE OF TECHNOLOGY \\ UNIVERSITY OF CALIFORNIA \\ MONTANA STATE UNIVERSITY \\ UNIVERSITY OF NEVADA \\ OREGON STATE COLLEGE \\ UNIVERSITY OF OREGON \\ UNIVERSITY OF SOUTHERN CALIFORNIA
}

\author{
STANFORD UNIVERSITY \\ UNIVERSITY OF UTAH \\ WASHINGTON STATE COLLEGE \\ UNIVERSITY OF WASHINGTON \\ AMERICAN MATHEMATICAL SOCIETY \\ CALIFORNIA RESEARCH CORPORATION \\ HUGHES AIRCRAFT COMPANY \\ THE RAMO-WOOLDRIDGE CORPORATION
}

Mathematical papers intended for publication in the Pacific Journal of Mathematics should be typewritten (double spaced), and the author should keep a complete copy. Manuscripts may be sent to any of the editors. All other communications to the editors should be addressed to the managing editor, E. G. Straus at the University of California, Los Angeles 24, California.

50 reprints per author of each article are furnished free of charge; additional copies may be obtained at cost in multiples of 50 .

The Pacific Journal of Mathematics is published quarterly, in March, June, September, and December. The price per volume (4 numbers) is $\$ 12.00$; single issues, $\$ 3.50$. Back numbers are available. Special price to individual faculty members of supporting institutions and to individual members of the American Mathematical Society: $\$ 4.00$ per volume; single issues, $\$ 1.25$.

Subscriptions, orders for back numbers, and changes of address should be sent to Pacific Journal of Mathematics, 2120 Oxford Street, Berkeley 4, California.

Printed at Kokusai Bunken Insatsusha (International Academic Printing Co., Ltd.), No. 6, 2-chome, Fujimi-cho, Chiyoda-ku, Tokyo, Japan.

\section{PUBLISHED BY PACIFIC JOURNAL OF MATHEMATICS, A NON-PROFIT CORPORATION}

The Supporting Institutions listed above contribute to the cost of publication of this Journal, but they are not owners or publishers and have no responsibility for its content or policies. 


\section{Pacific Journal of Mathematics}

\section{Vol. 8, No. 3 \\ May, 1958}

Michael Israel Aissen, A set function defined for convex plane domaines... . 383

Robert Ellis, Distal transformation groups ................... 401

Ciprian Foias, On a commutative extension of a commutative Banach algebra ....................................... 407

Jerry William Gaddum, Linear inequalities and quadratic forms ......... 411

Allen A. Goldstein and Elliott Ward Cheney, Jr., A finite algorithm for the solution of consistent linear equations and inequalities and for the Tchebycheff approximation of inconsistent linear equations...........

William L. Hart and T. S. Motzkin, Proof of the fundamental theorem on implicit functions by use of composite gradient corrections .......... 429

Henry Berge Helson, Conjugate series and a theorem of Paley .......... 437

Wu-Chung Hsiang, Abelian groups characterized by their independent subsets....................................... 447

John W. Lamperti, On the isometries of certain function-spaces ........ 459

Karel DeLeeuw and Walter Rudin, Extreme points and extremum problems

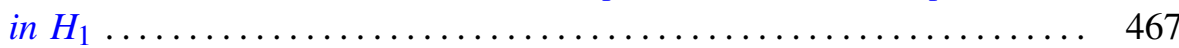

Eugene Lukacs, Some extensions of a theorem of Marcinkiewicz........ 487

George W. Mackey, Multiplicity free representations of finite groups ..... 503

Eben Matlis, Injective modules over Noetherian rings ............. 511

John William Neuberger, Continuous products and nonlinear integral equations

Lawrence Edward Payne and Hans F. Weinberger, New bounds for solutions of second order elliptic partial differential equations...

William T. Reid, A Prüfer transformation for differential systems ........ 575

Howard L. Rolf, The free lattice generated by a set of chains ...

K. M. Saksena, Inversion and representation theorems for a generalized

Laplace integral....................................... 597

Daniel Shanks, Two theorems of Gauss......................... 609

Paul Slepian, On the Lebesgue area of a doubled map ............... 613

Otto Szász and Nelson Paul Yeardley, Jr., The representation of an analytic function by general Laguerre series . ..................... 621

Alan C. Woods, On two-dimensional convex bodies ................. 635 